University of Montana

ScholarWorks at University of Montana

$12-14-2002$

\title{
Depth-varying constitutive properties observed in an isothermal glacier
}

H. P. Marshall

University of Colorado Boulder

Joel T. Harper

University of Montana - Missoula, joel.harper@mso.umt.edu

W. Tad Pfeffer

University of Colorado Boulder

Neil Humphrey

University of Wyoming

Follow this and additional works at: https://scholarworks.umt.edu/geosci_pubs

Part of the Earth Sciences Commons

Let us know how access to this document benefits you.

\section{Recommended Citation}

Marshall, H. P., J. T. Harper, W. T. Pfeffer, and N. F. Humphrey, Depth-varying constitutive properties

observed in an isothermal glacier, Geophys. Res. Lett., 29(23), 2146, doi:10.1029/2002GL015412, 2002.

This Article is brought to you for free and open access by the Geosciences at ScholarWorks at University of Montana. It has been accepted for inclusion in Geosciences Faculty Publications by an authorized administrator of

ScholarWorks at University of Montana. For more information, please contact scholarworks@mso.umt.edu. 


\title{
Depth-varying constitutive properties observed in an isothermal glacier
}

\author{
H. P. Marshall, ${ }^{1}$ J. T. Harper, ${ }^{2}$ W. T. Pfeffer, ${ }^{1}$ and N. F. Humphrey ${ }^{2}$ \\ Received 1 May 2002; revised 12 June 2002; accepted 11 July 2002; published 14 December 2002.
}

[1] Detailed three-dimensional in-situ measurements of deformation at depth are used to examine the rheology of a $6 \times 10^{6} \mathrm{~m}^{3}$ block of temperate glacier ice. Assuming that the viscosity of this ice is primarily dependent on stress, the relationship between inferred stress and measurements of strain-rate above $\sim 115 \mathrm{~m}$ depth suggest a constitutive relationship with a stress exponent $n \sim 1$. Deformation below $115 \mathrm{~m}$ is described by a non-linear flow law with a power exponent of approximately 3-4. A sharp transition between the two flow regimes is likely caused by a change in the dominant mechanism from superplastic flow, basal slip, and/or diffusional flow near the surface to dislocation and intragranular deformation at depth. INDEX TERMS: 1827 Hydrology: Glaciology (1863); 1863 Hydrology: Snow and Ice (1827); 3210 Mathematical Geophysics: Modeling; 3220 Mathematical Geophysics: Nonlinear dynamics; 1699 Global Change: General or miscellaneous. Citation: Marshall, H. P., J. T. Harper, W. T. Pfeffer, and N. F. Humphrey, Depth-varying constitutive properties observed in an isothermal glacier, Geophys. Res. Lett., 29(23), 2146, doi:10.1029/2002GL015412, 2002.

\section{Introduction}

[2] The rheological behavior of ice plays a pivotal role in predicting the response of glaciers and ice sheets to climate change, understanding the evolution of glacial landscapes, and assigning time-depth scales to ice cores for measurement of long-term climate history. Furthermore, the world's small temperate glaciers are the fastest-acting component of global glacier mass balance, and constitute a significant contribution to sea level change on century time-scales [Meier, 1984; Church et al., 2001]. The constitutive properties of temperate ice are therefore important for predictions of global response to climate change.

[3] While understanding of glacier and ice sheet mechanics has developed substantially during the last 50 years, the material properties of glacial ice are still not well established. Ice appears to deform solely in response to deviatoric stress with a stress dependent viscosity [Glen, 1955]. The commonly applied flow law for glacial ice gives the strain rate $\dot{\varepsilon}$ as a function of the deviatoric stress $\tau$, in the form $\dot{\varepsilon}=$ $A \tau^{n}$, where $A$ is a function of temperature and $n$ is a constant [Paterson, 1994]. Polynomial forms of the flow law have been proposed in the past [Lliboutry, 1969; Meier, 1960]

\footnotetext{
${ }^{1}$ Inst. of Arctic and Alpine Research and Dept. of Civil, Environmental, and Architectural Eng., University of Colorado at Boulder, Boulder, CO, USA.

${ }^{2}$ Dept. of Geology and Geophysics, University of Wyoming, Laramie, WY, USA.

Copyright 2002 by the American Geophysical Union. 0094-8276/02/2002GL015412
}

however they were never widely accepted due to a lack of high resolution observations necessary for verification.

[4] Through laboratory experiments and measurements on glaciers and ice sheets, a single value of $n$ appropriate for modeling glacial flow has been sought. Laboratory investigations allow accurate control of stress and strain-rate and detailed analysis of ice texture and fabric. Because a large accumulated strain is necessary to achieve steady-state creep (where natural glacier deformation occurs), most laboratory measurements have been performed at stresses much higher than those found in natural ice. Difficulties in representing natural conditions of polycrystalline glacier ice such as large crystals, widely ranging crystal sizes, and natural inhomogeneities, also makes the applicability of laboratory results to glaciers and ice sheets uncertain. Alternatively, in-situ strainrate observations in natural ice bodies are difficult to collect and may be related only to estimates of stress inferred from glacier geometry. As a consequence of the combined shortcomings of field and laboratory measurements, the appropriate flow law exponent $n$ has long been debated and remains an unresolved issue; 3 is the conventional value [Paterson, 1994], but values ranging from 1 to more than 4 have been used [Hooke, 1981]. Theoretically, ice should deform by several mechanisms that depend upon stress, temperature, and fabric, with different values of $n$ for each mechanism [Alley, 1992; Duval et al., 1983]. This is supported by observations of the spreading of Antarctic ice shelves [Doake and Wolff, 1985; Weertman, 1985] and laboratory experiments using new methods [Goldsby and Kohlstedt, 2001; Durham et al., 2001].

\section{High Resolution 3-D Deformation Data}

[5] We use a high resolution three-dimensional data set of deformation and related variables collected on Worthington Glacier, a temperate coastal Alaskan valley glacier, to evaluate the in-situ constitutive relationship in a block of natural glacial ice $198 \mathrm{~m}$ deep and $165 \times 240 \mathrm{~m}$ in lateral extent. Ice texture and fabric of the sample exhibit two characteristics relevant to deformation: 1) bubble content diminishes and crystal size increases roughly linearly with depth; and 2) macro-scale (greater than grain-scale) inhomogeneities, including water-filled cavities and clear ice layers, comprise less than $3 \%$ of the ice mass [Harper and Humphrey, 1995]. Temperate ice typically does not show preferred fabric except under exceptionally high strain-rate conditions, and given the conditions on Worthington Glacier it is very unlikely that any significant fabric would develop, especially in the near-surface low stress ice.

[6] Deformation of the block was evaluated by more than 21,000 measurements of the tilting of 31 boreholes (Figure 1) extending to a depth of 180-200 m, near the glacier bed [Harper et al., 2001]. Measurements were made 


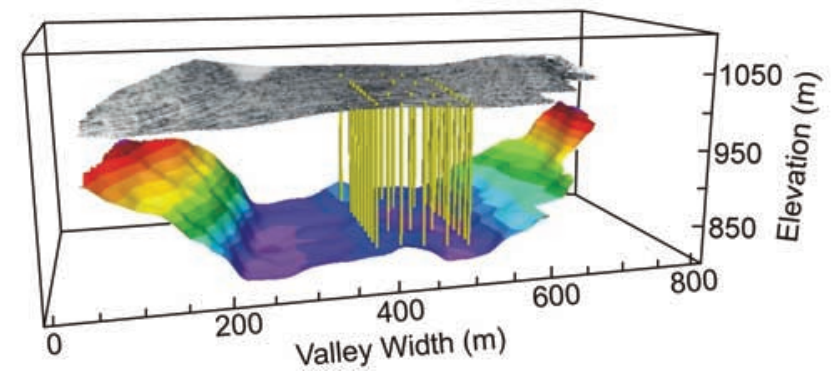

Figure 1. Surface and bed topography of study region with location of 31 boreholes. 3D deformation was determined from measurements of borehole tilt every $2 \mathrm{~m}$ to $180 \mathrm{~m}$ depth.

over periods of up to 60 days. The boreholes were displaced $10-15 \mathrm{~m}$ by down-glacier movement during the interval, and yielded the two horizontal components of the velocity vector. Thus, the measured strain-rate represents a spatial average over the hole's displacement path. These velocity data were then interpolated to a three-dimensional grid with vertical coordinates referenced to the irregular surface of the glacier [Harper et al., 2001]. The large grid $(24 \times 11 \times 99$ nodes) was used to calculate the strain-rate tensor, employing an adaptation of a standard finite element interpolation technique [Huebner et al., 2001].

\section{Analysis}

[7] We assume the ice is isotropic such that a flow law function $\lambda(\tau)$ relates the strain-rate tensor $\dot{\varepsilon}_{i j}$ to the deviatoric stress tensor $\tau_{i j}$ as $\dot{\varepsilon}_{i j}=\lambda(\tau) \tau_{i j}$ where $i$ and $j$ are index terms of the tensor quantities, and $\tau$ is the effective deviatoric stress. Video analysis of 16 boreholes throughout the study area (totaling more than $2750 \mathrm{~m}$ in length) indicate that the ice can be well represented as homogeneous, as the effect of crystal size, water and bubble content on the viscosity is expected to be small [Harper and Humphrey, 1995]. In addition, the study area of this temperate glacier is located in the ablation zone and below $\sim 20 \mathrm{~m}$ is nearly isothermal. Therefore, we assume that the flow law function $\lambda(\tau)$ depends only on the effective deviatoric stress $\tau$.

[8] We use a coordinate system with $x$ parallel to the regional surface and pointing in the down-flow direction, $y$ positive down and perpendicular to the surface, and $z$ across flow. Our measurements show that $\dot{\varepsilon}_{x y}$ dominates the strainrate tensor [Harper et al., 2001] as longitudinal and transverse gradients are small in comparison. In addition, the study block is located far from the valley walls, so deformation caused by transverse gradients in side drag should not be significant. Finally, direct measurement of the stress tensor at a single depth at this location showed a state of stress which generally matches that predicted by our assumption [Pfeffer et al., 2000]. $\tau_{x y} \approx$ driving stress $=f$ $\rho g h \sin \theta$ should therefore be valid, where $f$ is a "shape factor" to account for drag due to the valley walls, $\theta$ is the surface slope, $\rho$ is the density of ice, and $g=9.8 \mathrm{~m} / \mathrm{s}^{2}$.

[9] We calculated $\lambda(\tau)$ using this estimate of $\tau_{x y}$ and the measured shear strain-rate component $\dot{\varepsilon}_{x y}$. The remaining components of the deviatoric stress tensor were then determined from the corresponding strain-rate components by $\tau_{i j}=\dot{\varepsilon}_{i j} / \lambda(\tau)$. The stress and strain-rate tensors were used to compute the effective deviatoric stress $\tau$ and effective strain-rate $\dot{\varepsilon}$ at each of the $\sim 20,000$ elements throughout the study block. These values were then averaged horizontally ( 230 elements at each depth), and compared in log$\log$ space. The slope of the data in this form defines the exponent of the flow law $n$, and the y-intercept is directly related to the parameter $A$. We use two methods to calculate $\lambda(\tau)$ : one that relates strain-rates to far-field stresses, and a second that considers the influence of near-field stresses.

\subsection{Far-Field Stress Estimate}

[10] The mean strain-rate is related to the far-field stress, which we assume to be constant throughout the block at each depth. This is reasonable since previous work has shown that the surface slope $\theta$ should be averaged over a horizontal length scale equivalent to multiple ice depths [Kamb and Echelmeyer, 1986], while the dimensions of our block are of the order of 1 ice depth. Our approach differs from past analyse of field data [Raymond, 1980; Thorsteinsson et al., 1999; Dahl-Jensen and Gundestrup, 1987] in that we do not rely upon a priori assumptions about the form of the flow law, surface slope $\theta$, or valley geometry. In addition, because the three-dimensional strain-rate tensor $\dot{\varepsilon}_{i j}$ was measured, it is not necessary to make the assumption of simple shear (i.e. $\dot{\varepsilon}_{x y}$ and $\tau_{x y}$ are the only non-zero components of $\dot{\varepsilon}_{i j}$ and $\tau_{i j}$ ) which has often been done previously. Therefore, as the surface is approached and other components of $\dot{\varepsilon}_{i j}$ become significant, as long as $\tau_{x y}$ is roughly proportional to depth and the ice is reasonably isotropic and homogeneous, our conclusions will be valid. Because of the uncertainty in the shape function $f$ and the length scale over which $\theta$ should be calculated, we hesitate to provide an estimate of the flow law parameter $A$. Our conclusions about the flow law exponent $n$, however, are unaffected by the choice of these geometrical parameters.

\subsection{Influence of Near-Field Stresses}

[11] Due to the non-linearity of ice, averaging of strainrates over all points at a particular depth may introduce systematic error when the strain-rate field contains nonrandom spatial variability. In the lower half of the glacier's thickness the strain-rate tensor is dominated by shear in the vertical/along-flow plane $\left(\dot{\varepsilon}_{x y}\right)$, showing little change laterally over the block [Harper et al., 1998]. In contrast, near the surface $\tau_{x y}$ diminishes and the flow field exhibits shortlength scale (i.e., 10's of meters) variability in the horizontal [Harper et al., 2001]. This is likely due to short-length scale variations in the stress field arising from short length-scale variations in surface slope $\theta$. Averaging short-scale measurements of strain-rate over large areas in a horizontal plane includes values arising from small variations in driving stress, but calculating driving stress from the large-scale geometry will not include those small variations. Consequently, far-field averaging may be bigger by short-length scale variability present in strain-rates but not in stresses.

[12] This bias is avoided by our near-field case, where driving stresses and strain-rates are calculated at the same length scale. At each depth $Y$, the strain-rate tensor $\dot{\varepsilon}_{i j}$ was averaged over a circular area $\mathrm{A}_{\mathrm{z}}$ with a radius $R$ equal to the depth $\mathrm{z}$. The driving stress $\tau_{x y}$ was then computed from the surface slope $\theta$, in the direction of flow, averaged over an area equivalent to $A_{z}$. The strain-rate tensor was transformed to 

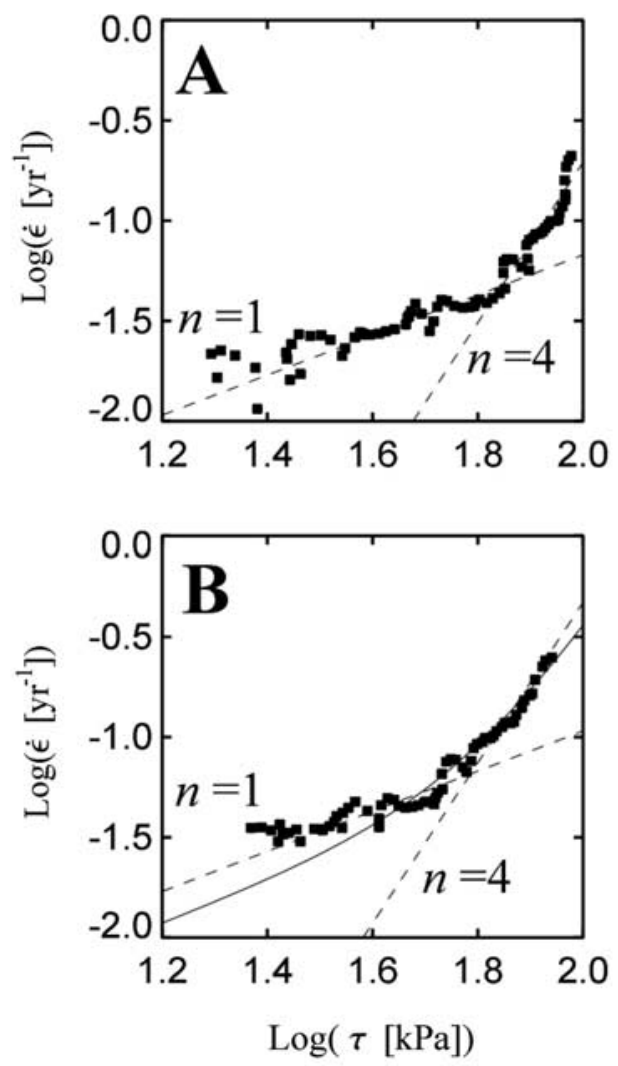

Figure 2. Log-log plot of effective deviatoric stress $\tau$ vs. effective $\dot{\varepsilon}$ strain-rate. Data are shown at $2 \mathrm{~m}$ increments between $\sim 30$ and $180 \mathrm{~m}$ depth in the glacier; each data point represents $\sim 230$ elements averaged at a given depth. Straight dashed lines: power exponents of $n=1$ and $n=4$; Solid line: Goldsby and Kohlstedt [2001] type model fit to data. (a) Far-field stress calculation; (b) Near-field stress calculation. Regardless of the choice of geometrical parameters, our data indicate linear viscous flow in the upper half of the glacier (low stress), and a power law with $n=3-4$ in the deeper half.

this local coordinate system, and as before, $\lambda(\tau)$ was used to find the effective stress and effective strain-rate at each of the $\sim 20,000$ elements. These quantities were then averaged at each depth.

\section{Results and Discussion}

[13] The horizontally averaged effective stress and effective strain-rate are shown in log-log space in Figure 2. The slope of the data in this form defines the exponent of the flow law. Both the near-field and far-field analysis suggest an approximately linear relation between stress and strain-rate at stresses lower than $\sim 50-75 \mathrm{kPa}$, and a non-linear relationship at higher stresses. Near the surface the data scatter about a value of $n=1$, whereas at depth $n \sim 4$. In both the far-field and near-field cases the transition between these two regimes is abrupt, occurring at $\sim 115 \mathrm{~m}$ depth for far-field averaging (Figure $2 \mathrm{a}$ ) and at $\sim 75 \mathrm{~m}$ for near-field averaging (Figure 2b). The near-field case (Figure $2 b$ ) produces less scatter in the low stress region, illustrating the influence of slight variations in surface slope on near-surface flow.
[14] At low stresses, high temperature metals [Harper and Dorn, 1957; Servi and Grant, 1951] and other crystalline solids undergo deformation dominated by grain boundary sliding, dislocation climb, self-directed diffusion of vacancies and other intergranular types of deformation for which the creep rate is roughly proportional to the applied stress [Weertman, 1985; De La Chapelle et al., 1999]. Grain-scale deformation processes are difficult to observe in the field. Recent laboratory work [Goldsby and Kohlstedt, 2001] on fine-grained ice $(\sim 3-200 \mu \mathrm{m})$ has provided clear evidence of three stress-dependent deformation mechanisms: (1) a dislocation creep at high stress regime characterized by a stress exponent of 4.0, (2) superplastic flow below $\sim 100 \mathrm{kPa}$, with $n=1.8$ and a grain size dependence, and (3) basal slip with $n=2.4$ and no grain size dependence. Their work also suggests that a fourth creep regime exists at even lower stresses (diffusional flow), with $n=1$ and a strong grain size dependence, but the time required to reach steady-state creep at these low stresses was too great, even for the smallest grain sizes $(\sim 3 \mu \mathrm{m})$. Other recent laboratory work [Durham et al., 2001] has shown that $n=4$ for dislocation creep, and confirms the existence of a grain sizesensitive creep regime where $n \sim 2$. It has been suggested [Peltier et al., 2000] that the traditional Glen flow law with $n=3$ [Glen, 1955], which has been widely used in the past, is suitable for a wide range of conditions due to the combined effect of superplastic deformation $(n=1.8)$ and dislocation creep $(n=4.0)$.

[15] The shift in the power law exponent $n$ identified in our data set is most likely caused by changes in the dominant mechanism of deformation. Given the range of stresses found in our sample $(\sim 10-100 \mathrm{kPa})$, we can expect all four creep regimes discussed above to be important. Although the laboratory experiments were performed on ice with grain sizes much smaller (of order $\mu m$ ) than those found in temperate ice (of order $\mathrm{cm}$ ), they provide detailed information about the deformation mechanisms. In contrast, fieldbased observations allow ice in its natural form to be studied without the complication of extrapolating results to realistic grain sizes, since the ice has already attained steady creep. The disadvantage to field-based measurements, however, is that other parameters can't be controlled. Deformation of temperate ice is less complicated than polar ice, as grain size variations are much smaller and temperature does not vary significantly with depth (within $\sim 0.05^{\circ} \mathrm{C}$ of the pressure melting point [Harrison, 1972]). Possibly characteristics of the ice such as water content, crystal size, and bubble content could be affecting our results, however borehole video photography has indicated that this temperate ice is reasonably homogeneous [Harper and Humphrey, 1995].

[16] Grain sizes were qualitatively observed to vary both on the surface and with depth (from borehole photography), but to an extent that the effect on the viscosity is expected to be small [Harper and Humphrey, 1995]. Although we can't distinguish between the superplastic $(n=1.8)$, basal slip $(n=2.4)$, and diffusion $(n=1)$ mechanisms due to a lack of grain size information, this data does provide field verification of a change in dominant deformation mechanism at low stress in temperate ice, which was not possible in many previous studies due to a lack of high resolution measurements. We note that the transition between processes is also temperature controlled [Goldsby and Kohlstedt, 2001]; as 
our data is derived from nearly isothermal ice $\left(T(z) \approx 0{ }^{\circ} \mathrm{C}\right)$, this complication is negligible in our analysis.

[17] Scatter in the stress/strain-rate relationship in our low stress measurements may result from errors in the calculation of stresses, or true noise in the relationship. Measurement errors in the original strain data decrease as the surface is approached [Harper et al., 2001], and are therefore not believed to be responsible for the scatter; imperfect evaluation of small variations in shear stress is more likely. Grain size-sensitive processes will also produce scatter. The strainrate in the superplastic regime is proportional to the inverse of the grain size raised to a power of 1.4 [Goldsby and Kohlstedt, 2001]. In our data, the grain size must vary by about $5-10 \%$ for diffusional flow to account for all of the observed variability, and borehole video observations suggest that grain size variations of up to $20 \%$ are well within reason. Unfortunately, we have no way of separating scatter resulting from stress calculations from scatter due to grain size-sensitive mechanisms.

[18] The solid line in Figure 2b is a model of the form proposed by Goldsby and Kohlstedt [2001], which is a linear combination of diffusion type flow $(n=1)$ and dislocation creep $(n=4)$. The model underestimates strain-rates very close to the surface, although the log-log plot exaggerates the discrepancy at small strain-rate values ( $\sigma=$ standard deviation of the model fit $\left.=0.0107 \mathrm{yr}^{-} 1\right)$. Adding terms representing superplastic flow and basal slip did not significantly improve the fit.

\section{Conclusion}

[19] Despite 3\% macro-scale inhomogeneities in our glacial-scale sample, our findings support multiple modes of deformation inferred from laboratory and theoretical investigations. The stress level at which the dominant deformation mechanism changes may preclude a significant role for linear creep in ice sheets, however, since locations of low stress in ice sheets are usually well below the melting point. This study demonstrates that deformation of mountain glaciers, which have sustained a complex strain history and have large-scale defects such as crevasses and internal hydrological pathways, is controlled by grain-scale processes. The deformation observed in the upper half of this $200 \mathrm{~m}$ thick glacier implies that much of the ice in the world's small mountain glaciers may best be defined by a power law with $n \approx 1-2$. In addition, deformation is likely to be more complex than assumed; for example, where background stresses are near the threshold for change in mode of deformation, stress concentrations such as the upstream and downstream sides of bedrock bumps may switch between linear and non-linear dominated deformation. The first fully three-dimensional observation of ice deformation indicates that we must consider multiple deformation mechanisms in order to comprehensively understand the flow of temperate glaciers.

[20] Acknowledgments. Thanks to R. S. Anderson (University of California, Santa Cruz) and two anonymous reviewers whose comments greatly improvedthis manuscript. Funded by NSF-EAR-9901492 (J. T. Harper), NSF-OPP-9531565 (N. F. Humphrey), and NSF-OPP-9531550 (W. T. Pfeffer).

\section{References}

Alley, R., Flow-law hypotheses for ice-sheet modeling, J. Glaciol., 38(129), 245-256, 1992.

Church, J., et al., in Climate Change 2001 - The Scientific Basis. Contribution of Working Group 1 to the Third Assessment Report of the Intergovernmental Panel on Climate Change, edited by J. T. Houghton et al., pp. 527, Cambridge Univ. Press, Cambridge, 2001.

Dahl-Jensen, D., and N. S. Gundestrup, Constitutive properties of ice at Dye 3, Greenland, in Proc. of the Vancouver Symposium, IAHS Pub No. 170, 32-43, 1987.

De La Chapelle, S., H. Milsch, O. Castelnau, and P. Duval, Compressive creep of ice containing a liquid intergranular phase: rate-controlling processes in the dislocation creep regime, Geophys. Res. Lett., 26(2), $251-$ 254, 1999.

Doake, C. S. M., and W. W. Wolff, Flow law for ice in polar ice sheets, Nature, 314, 255-257, 1985.

Durham, W. B., L. A. Stern, and S. H. Kirby, Rheology of ice I at low stress and elevated confining pressure, J. Geophys. Res., 106(B6), 11,031$11,042,2001$

Duval, P., M. Ashby, and I. Anderman, Rate-controlling processes in the creep of polycrystalline ice, J. Phys. Chem, 87, 4066-4074, 1983.

Glen, J. W., The creep of polycrystalline ice, Proc. R. Soc. London Ser. A, $228,519-538,1955$.

Goldsby, D. L., and D. L. Kohlstedt, Superplastic deformation of ice: Experimental observations, J. Geophys. Res., 106(B6), 11,017-11,030, 2001.

Harper, J., and J. Dorn, Viscous creep of aluminum near its melting temperature, Acta Metallurgica, 5, 654-665, 1957.

Harper, J. T., and N. F. Humphrey, Borehole video analysis of a temperate glacier's englacial and subglacial structure - implications for glacier flow models, Geology, 23(10), 901-904, 1995.

Harper, J. T., N. F. Humphrey, and W. T. Pfeffer, Three-dimensional deformation measured in an Alaskan glacier, Science, 281, 1340-1342, 1998.

Harper, J. T., et al., Spatial variability in the flow of a valley glacier: deformation of a large array of boreholes, J. Geophys. Res., 106(B5), $8547-8562,2001$

Harrison, W. D., Temperature of a temperate glacier, J. Glaciol., 11(61), $15-29,1972$.

Hooke, R. L. B., Flow law for polycrystalline ice in glaciers - comparison of theoretical predictions, laboratory data, and field-measurements, $R e$ views of Geophysics, 19(4), 664-672, 1981.

Huebner, K. H., D. L. Dewhirst, D. E. Smith, and T. G. Byrom, The Finite Element Method for Engineers, pp. 29-33, Wiley, New York, ed. 4, 2001.

Kamb, B., and K. A. Echelmeyer, Stress-gradient coupling in glacier flow 1: Longitudinal averaging of the influence of ice thickness and surface slope, J. Glaciol., 32(111), 267-284, 1986.

Lliboutry, L., The dynamics of temperate glaciers from the detailed viewpoint, Journal of Glaciology, 8(53), 185-205, 1969.

Meier, M. F., Mode of Flow of Saskatchewan Glacier, U.S. Geological Survey Tech. Rep. 351, 70 pp., 1960.

Meier, M. F., Contribution of small glaciers to global sea level, Science, 226, 1418-1421, 1984

Paterson, W. S. B., Physics of Glaciers, pp. 480, Pergamon, New York, ed. 3, 1994.

Peltier, W. R., D. L. Goldsby, D. L. Kohlstedt, and L. Tarasov, Ice-age icesheet rheology: Constraints from the Last Glacial Maximum form of the Laurentide ice sheet, Ann. Glaciol., 30, 163-176, 2000.

Pfeffer, W. T., N. F. Humphrey, B. Amadei, J. T. Harper, and J. Wegmann, In-situ stress tensor measured in an Alaskan glacier, Ann. of Glac., 31, 229-235, 2000 .

Raymond, C. F., Temperate valley glaciers, in Dynamics of Snow and Ice Masses, edited by S. Colbeck, chap. 2, Academic Press, New York, 1980.

Servi, I., and N. Grant, Structure observations of aluminum deformed in creep at elevated temperatures, Journal of Metals, 3, 917-922, 1951.

Thorsteinsson, T., E. Waddington, K. Taylor, R. Alley, and D. Blankenship, Strain-rate enhancement at Dye 3, Greenland, J. Glaciol., 45(150), 338345,1999

Weertman, J., Unsolved problems of creep, Nature, 314, 227, 1985.

H. P. Marshall and W. T. Pfeffer, Institute of Arctic and Alpine Research, University of Colorado at Boulder, Department of Civil, Environmental, and Architectural Engineering, 1560 30th St, Campus Box 450 Boulder, CO 80309, USA. (marshalh@colorado.edu; pfeffer@tintin.colorado.edu)

J. T. Harper and N. F. Humphrey, Department of Geology and Geophysics, University of Wyoming, Laramie, WY 82071-3006, USA. (joelh@uwyo.edu; neil@uwyo.edu) 